\title{
Rancang Bangun Alat Eksperimen Sederhana Gerak Proyektil
}

\author{
Pradita Adnan Wijaya \\ Sekolah Pascasarjana Pengajaran Fisika, Institut Teknologi Bandung \\ Jl. Ganesa I0 Bandung 40132
}

Umar Fauzi, Fourier Dzar Eljabbar Latief

Departemen Fisika, FMIPA, Institut Teknologi Bandung

J1. Ganesa I0 Bandung 40132

\section{Thoha Firdaus}

Program Studi Pendidikan Fisika, STKIP Nurul Huda, Sumatera Selatan

Jalan Kota Baru Sukaraja Buay Madang OKU Timur Stkip Nurul Huda, OKU TIMUR

Surat-e: pradita.a.wijaya@gmail.com

Menentukan gerak proyektil merupakan permasalahan penting dalam sejarah perkembangan ilmu mekanika. Gerak proyektil adalah gerak suatu benda yang diberi kecepatan awal, kemudian menempuh lintasan yang arahnya sepenuhnya dipengaruhi oleh percepatan gravitasi dan hambatan udara. Untuk mempermudah pemahaman peserta didik mengenai materi gerak proyektil, telah dibuat suatu alat eksperimen gerak proyektil sederhana. Diharapkan alat ini dapat digunakan sebagai media pembelajaran yang mudah diaplikasikan, ditiru dan terjangkau bagi pihak sekolah maupun lembaga pendidikan.

Determining projectile motion is an important issue in the history of the development of mechanics. The motion of a projectile is the motion of an object given the initial velocity, then travels the path whose direction is completely influenced by the acceleration of gravity and air resistance. To facilitate students' understanding of projectile motion material, a simple projectile motion experiments tool has been developed. It is expected that this tool can be used as a learning media that is easy to apply, imitated and affordable for schools and educational institutions.

Kata kunci: gerak proyektil, alat eksperimen, media pembelajaran

\section{Pendahuluan}

Menentukan gerak proyektil merupakan permasalahan penting dalam sejarah perkembangan ilmu mekanika[I]. Gerak proyektil didefinisikan sebagai gerak suatu benda yang diberi kecepatan awal, kemudian menempuh lintasan yang arahnya sepenuhnya dipengaruhi oleh percepatan gravitasi dan hambatan udara[2]. Untuk mempermudah pemahaman mengenai gerak proyektil, diperlukan media pembelajaran berupa alat eksperimen gerak proyektil yang terjangkau dan dapat dengan mudah dioperasikan oleh siswa. Saat ini, alat peraga yang ada merupakan buatan luar negeri, seperti produk dari PASCO[3] dan VERNIER[4] yang harganya cukup mahal. Oleh karena itu, rancang bangun alat eksperimen sederhana mengenai gerak proyektil bagi peserta didik perlu dilakukan.

\section{Kajian Pustaka}

Persamaan mengenai gerak proyektil yang ditunjukkan pada persamaan I (pada ruang hampa udara) dan 2 (dengan memperhitungkan hambatan udara) [I].

$$
\begin{aligned}
& m \frac{d^{2} r}{d t^{2}}=-m g \hat{z} \\
& m \frac{d^{2} r}{d t^{2}}=-m g \hat{z}-b \frac{d r}{d t}
\end{aligned}
$$


$m$ merupakan massa partikel (kg), g merupakan percepatan gravitasi $\left(\mathrm{m} / \mathrm{s}^{2}\right), t$ merupakan waktu $(\mathrm{s})$, dan $b$ merupakan koefisien hambatan udara atau drag.

Secara umum gerak proyektil dapat ditinjau pada I, 2 maupun 3 dimensi yang mana vektor gerak proyektil dapat dilihat pada gambar I berikut.

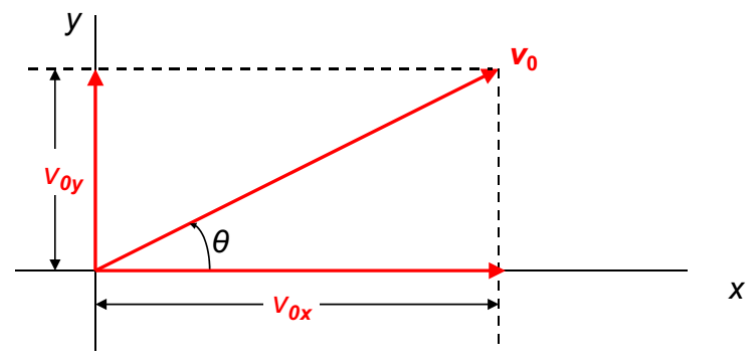

Gambar I. Komponen-komponen kecepatan awal sebuah proyektil dengan $\theta$ adalah sudut antara $v_{0}$ dengan sumbu horizontal $x$

\section{Gerak proyektil di kondisi vakum}

Dalam kondisi vacuum (hampa udara), misalkan kita luncurkan sebuah proyektil dari titik asal dengan kelajuan awal $v_{0}$ dengan sudut $\theta$ terhadap sumbu horisontal, maka kecepatan awal mempunyai komponen:

$$
\begin{aligned}
& v_{o x}=v_{0} \cos \theta \\
& v_{o y}=v_{0} \sin \theta
\end{aligned}
$$

Karena tidak ada percepatan horisontal, kecepatan komponen $x$ adalah konstan sebagaimana ditunjukkan pada persamaan (5).

$$
v_{y}=v_{0 x}
$$

Komponen y berubah terhadap waktu sesuai persamaan (6).

$$
v_{y}=v_{0 y}-g t
$$

Komponen perpindahan proyektil pada arah $x$ dan $y$ ditunjukkan oleh persamaan (7) dan (8).

$$
\begin{aligned}
& \Delta x=v_{0 x} t \\
& \Delta y=v_{0 y} t-\frac{1}{2} g t^{2}
\end{aligned}
$$

Persamaan umum untuk lintasan $y(x)$ dapat diperoleh dari persamaan (7) dan (8) dengan mengeleminasi variabel $t$ antara kedua persamaan ini dengan memilih $x_{0}=y_{0}=0$ dan dengan menggunakan $t=\frac{x}{v_{0 x}}$ pada persamaan (8) kita dapatkan persamaan (9)

$$
y=\left(\frac{v_{0 y}}{v_{0 x}}\right) x-\frac{1}{2}\left(\frac{g}{v_{0 x}^{2}}\right) x^{2}
$$

Waktu yang dibutuhkan proyektil untuk mencapai ketinggian maksimumnya dimana ketinggian awal dan akhir sama didapatkan dengan mengambil komponen vertikal kecepatannya sama dengan nol $v_{y}=-g t=0$ atau $t=\frac{v_{0 y}}{g}$.

Setelah diketahui $v_{y}$ dan $t$, selanjutnya kita dapat menentukan jarak jangkauan maksimum proyektil dalam kondisi vacuum maupun dengan memperhitungkan drag. Dimana vector gerak proyektil dapat dilihat pada gambar 2 berikut.

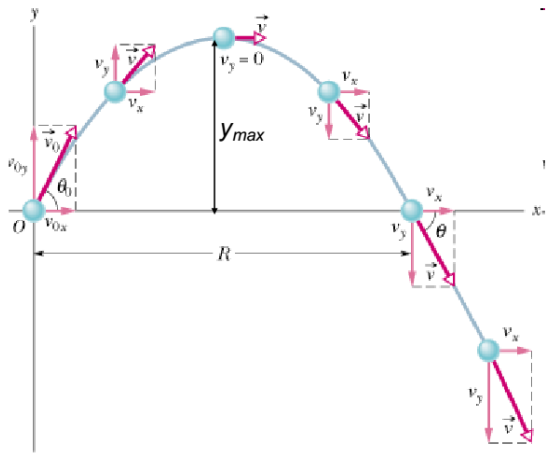

Gambar 2. Vektor gerak proyektil [5]

Jangkauan $R$ adalah jarak yang ditempuh dalam dua kali waktu ini sehingga persamaannya menjadi persamaan (I0).

$$
R=2 v_{0 x}\left(\frac{v_{0 y}}{g}\right)=\left(\frac{2 v_{0 x} v_{0 y}}{g}\right)
$$

Bila dinyatakan dalam kelajuan awal $v_{0}$ dan sudut lemparan $\theta$, jangkauan ini dapat dituliskan sebagaimana persamaan (II).

$$
R=\frac{v_{0}^{2}}{g} \sin 2 \theta
$$

\section{Gerak Proyektil dengan Memperhitungkan Drag}

Jika diasumsikan ada drag yang bekerja ke arah sumbu x sebesar $b$, maka persamaan gerak proyektil yang terjadi dapat ditulis sebagaimana persamaan 12 dengan $b V$ adalah $\operatorname{drag}(N)$.

$$
-b V=m \frac{d v}{d t}
$$

Karena adanya pengaruh gaya gravitasi, persamaan gerak proyektil ke arah sumbu $y$ dapat dituliskan sebagaimana persamaan I3.

$$
-b v-m g=m \frac{d v}{d t}
$$

Untuk mendapatkan nilai kecepatan gerak gerak proyektil, maka integrasi terhadap persamaan I4 untuk gerak kearah sumbu $x$ dan persamaan I5 untuk gerak 
kearah sumbu y. Hasilnya ditunjukkan pada persamaan I4 dan I5.

$$
\begin{aligned}
& v_{x}=v_{0} \cos \alpha e^{-\frac{b t}{m}} \\
& v_{y}=\left[\left(v_{0} \sin \alpha+\frac{m g}{b}\right) e^{-\frac{b t}{m}}\right]-\frac{m g}{b}
\end{aligned}
$$

Jarak luncur gerak proyektil juga dapat dihitung dengan mengintegrasikan persamaan I4 terhadap waktu $(t)$ untuk gerak proyektil ke arah sumbu $x$ dan persamaan I5 untuk gerak proyektil ke arah sumbu y. Persamaan hasil integrasi ditunjukkan oleh:

$$
\begin{gathered}
x=-\frac{m v_{0 x}}{b}\left(e^{-\frac{b t}{m}}-1\right) \\
y=\frac{m}{b} v_{0} \sin \alpha\left(1-e^{-\frac{b t}{m}}\right)-\frac{m^{2} g}{b^{2}}\left(e^{-\frac{b t}{m}}-1\right)-\frac{m g t}{b}
\end{gathered}
$$

\section{Rancangan Alat}

\section{Desain Alat}

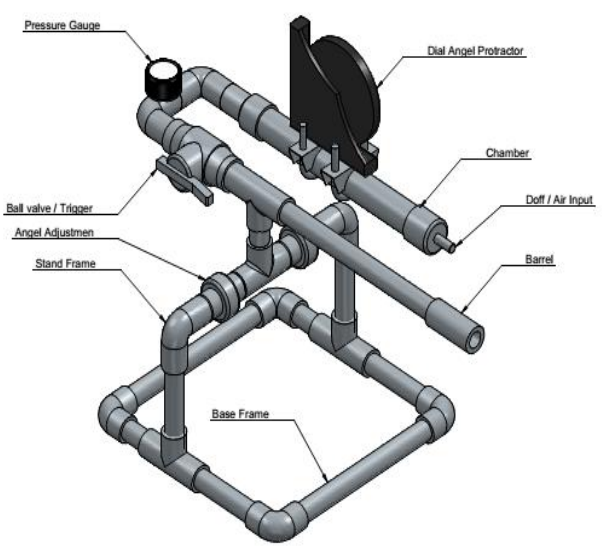

Gambar 3. Detail bagian-bagian alat

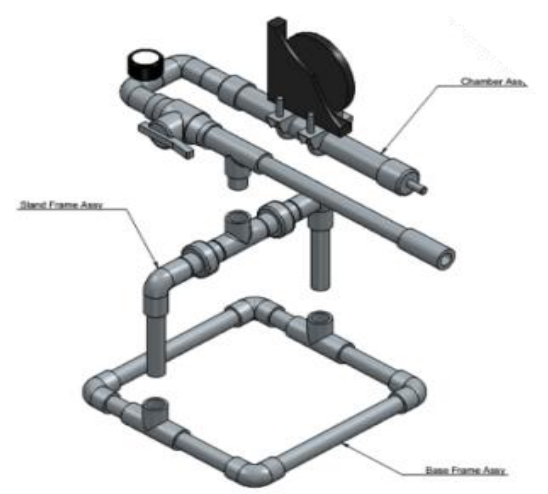

Gambar 5. Skema sistem bongkar pasang

\section{Alat dan Bahan}

Dalam pembuatan alat eksperimen gerak proyektil ini daftar item bahan pembuatan alat disajikan oleh tabel I.

\begin{tabular}{clc}
\multicolumn{3}{c}{ Tabel I. Daftar item bahan pembuatan alat } \\
\hline No & \multicolumn{1}{c}{ Nama Barang } & Item \\
\hline I & PVC & I \\
2 & Keni L & 8 \\
3 & Keni T & 4 \\
4 & Tutup I" & I \\
5 & Sambungan & I \\
6 & Kran I/2" & I \\
7 & Dop & I \\
8 & Angle adjusment & 2 \\
9 & Baut & 2 \\
I0 & Pressure gauge & I \\
II & Busur & I \\
I2 & Lem pvc & I \\
I3 & Pompa & I \\
\hline \hline
\end{tabular}

\section{Metode Eksperimen}

Teknik pengambilan data eksperimen gerak proyektil untuk menguji kinerja alat digambarkan melalui diagram alir pada gambar 4.

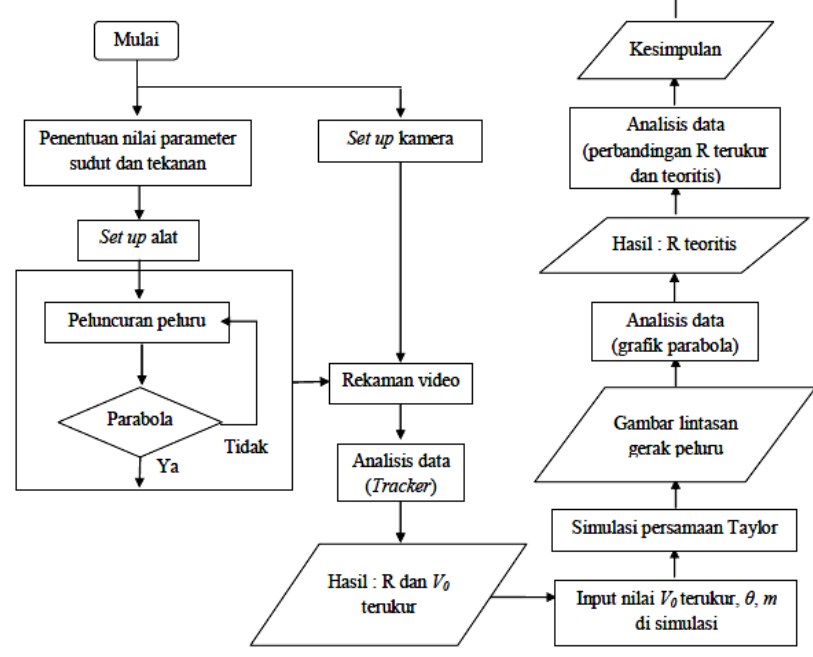

Gambar 4. Diagram alir ujicoba alat eksperimen gerak proyektil.

Penelitian diawali dengan penentuan nilai parameter yaitu sudut dan tekanan yang tetap. Selanjutnya, dilakukan analisis video luncuran gerak proyektil di laboratorium menggunakan software Tracker. Hasil analisis video tersebut kemudian dibandingkan dengan hasil simulasi numerik menggunakan Visual Basic for 
Applications (VBA) pada Microsoft Excel menggunakan parameter kecepatan $\left(V_{0}\right)$, sudut $(\theta)$, dan massa proyektil (m) yang sesuai dengan alat eksperimen. Diharapkan hasil analisis menggunakan kedua metode ini dapat dipergunakan untuk mengetahui akurasi serta menguji kinerja alat yang telah dibuat. Set up alat eksperimen ditunjukkan oleh gambar 5 .

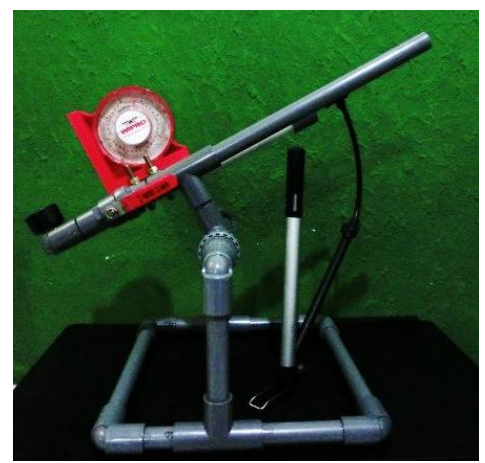

Gambar 5. Peluncur proyektil (tampak samping)

Pompa digunakan untuk memberikan tekanan udara ke dalam chamber. Nilai tekanan udara dapat diketahui dengan melihat pressure gauge. Apabila nilai tekanan udara sudah sesuai, proyektil dapat diluncurkan dengan membuka trigger.

\section{Hasil dan Pembahasan}

Dengan menentukan parameter sudut dan tekanan yang tetap, yaitu sebesar $60^{\circ}$ dan I0 psi (berurutan), diperoleh hasil sebagaimana yang tecantum pada tabel 2 .

Tabel 2. Hasil ujicoba alat eksperimen peluncur proyektil

\begin{tabular}{ccccc}
\hline$\theta\left({ }^{0}\right)$ & $v_{0}(\mathrm{~m} / \mathrm{s})$ & $\begin{array}{c}R \text { terukur } \\
(\mathrm{m})\end{array}$ & $\begin{array}{c}R \text { teoritis } \\
(\mathrm{m})\end{array}$ & $\mathcal{E}_{R(\%)}$ \\
\hline 60 & 2.53 & 1.87 & 1.90 & $-1,58$ \\
60 & 1.77 & 2.47 & 2.20 & 12,27 \\
60 & 1.89 & 1.89 & 1.30 & 45,38 \\
\hline \hline
\end{tabular}

Berdasarkan tabel 2, terlihat bahwa hasil nilai jarak ( $\left.R_{\text {terukur }}\right)$ yang didapatkan dari analisis menggunakan software Tracker menunjukkan inkonsistensi data. Perhitungan $R_{\text {terukur }}$ seharusnya mendekati hasil simulasi yang menggunakan persamaan (I6), sementara perhitungan $R_{\text {teoritis }}$ menggunakan simulasi yang beradasar pada persamaan (II). Dengan membandingkan kedua persamaan tersebut secara eksplisit, hasil yang didapatkan seharusnya menunjukkan bahwa $R_{\text {terukur }}$ selalu lebih kecil dari $R_{\text {teoritis. }}$ Hal ini dikarenakan pada $R_{\text {terukur }}$ terdapat gaya hambatan udara (drag) yang bekerja berlawanan arah dengan gerak luncuran proyektil. Dari tabel 2, terlihat hanya percobaan pertama yang sesuai dengan ketentuan tersebut
Inkonsistensi data yang terjadi kemungkinan diakibatkan oleh alat yang belum terkalibrasi sempurna. Dari segi alat yang masih dalam tahap pengembangan, tingkat presisinya masih rendah. Hal ini dikarenakan karena pressure gauge dan protactor yang digunakan masih dalam sistem analog, sehingga pembacaan nilai yang terukur menjadi kurang akurat. Di samping itu, ball valve (trigger/kran) yang digunakan masih memberikan pengaruh pada proses keluarnya udara. Ketika diberikan tekanan udara yang sama, terjadi perbedaan kecepatan awal $\left(V_{0}\right)$ yang keluar dan mendorong peluru, sehingga jarak jangkau $(R)$ yang dihasilkan berbeda. Perbedaan yang terjadi bisa dikarenakan oleh kecepatan membuka kran, cara membuka kran, maupun waktu jeda antara proses memompa udara dan proses membuka trigger: Oleh karena itu, diperlukan model trigger dengan sistem digital yang dapat terbuka secara otomatis ketika tekanan udara sudah sesuai yang diinginkan.

Selain dari kondisi trigger tersebut, adanya goncangan alat yang diakibatkan oleh gerakan tangan ketika membuka trigger juga memberikan ketidakakuratan pada alat. Goncangan yang terjadi kemungkinan dapat mengkibatkan perubahan sudut luncuran $(\boldsymbol{\theta})$ yang sudah diatur sebelumnya. Perubahan terhadap sudut luncuran ini akan mengakibatkan perubahan pada jarak luncuran $(R)$ serta bentuk lintasan proyektil yang dihasilkan.

\section{Saran Pengembangan}

Untuk perbaikan kualitas alat, maka pada tahap pengembangan selanjutnya sebaiknya bagian alat yang berupa angle protactor dan pressure gauge diganti menggunakan sistem digital agar pembacaannya lebih akurat. Selain itu, trigger yang berupa kran ball valve juga sebaiknya diganti dengan trigger otomatis seperti model solenoida valve. Hal ini dimaksudkan untuk meminimalkan efek goncangan dan menjaga stabilitas tekanan yang akan mendorong luncuran proyektil.

\section{Kesimpulan}

Alat eksperimen gerak proyektil yang dihasilkan telah berhasil menunjukkan kinerjanya sebagai media pembelajaran gerak proyektil. Hasil ujicoba kualitas alat menunjukkan bahwa kinerja alat belum maksimal. Hal ini terlihat dari inkonsistensi data yang dihasilkan ketika ujicoba peluncuran proyektil dengan kondisi awal (tekanan dan sudut luncuran) yang sama ternyata memberikan hasil kecepatan awal $\left(v_{0}\right)$ dan jarak luncuran $(R)$ yang berbeda. 


\section{Ucapan Terimakasih}

Ucapan terimakasih penulis sampaikan kepada Prof. Dr. rer nat Umar Fauzi dan Dr. Fourier Dzar Eljabbar Latief atas bimbingannya, serta sdr. Candra Irawan yang telah membuatkan desain dan prototype alat eksperimen gerak proyektil ini.

\section{Kepustakaan}

[1] Symon, Keith R. 1974. Mechanics $3^{\text {rd }}$ Edition. Addison-Wesley Publishing Company, Inc.

[2] Young, Hugh D. dan Freedman, Roger A. 2002. Fisika Unversitas Jilid I. Jakarta: Erlangga.

[3] https://www.pasco.com/prodCompare/projectile-launchers/

[4] https://www.vernier.com/experiments/pwv/8b/projectile_mo tion_launcher/

[5] http://demo.webassign.net/ebooks/hrw8demo/art/images/ha lliday8019c04/image_t/tfgOIO.gif 